Original Research Paper

\title{
Effects of Nitrogen Source on the Lipid Accumulation in Phaeodactylum Tricornutum
}

\author{
Xiaojie Ren, Qi Yan, Song Li, Yusuf Nazir, Hafiy Halim, Xinhe Zhao and Yuanda Song \\ Colin Ratledge Center for Microbial Lipids, \\ School of Agriculture Engineering and Food Science, Shandong University of Technology, Zibo, China
}

\begin{abstract}
Article history
Received: 18-06-2020

Revised: $17-07-2020$

Accepted: 25-07-2020

Corresponding Author:

Xinhe Zhao

Colin Ratledge Center for

Microbial Lipids, School of

Agriculture Engineering and

Food Science, Shandong

University of Technology,

Zibo, China

Email: zhaoxinhe2018@163.com

Yuanda Song

Colin Ratledge Center for

Microbial Lipids, School of

Agriculture Engineering and

Food Science, Shandong

University of Technology,

Zibo, China

Email: ysong@sdut.edu.cn
\end{abstract}

\begin{abstract}
Nitrogen source has an important influence on the growth and lipid synthesis of Phaeodactylum tricornutum. It affects lipid accumulation through global metabolic regulation. However, little research has been done on the correlation between other metabolites and lipid metabolism during the synthesis of Phaeodactylum tricornutum. In this study, we studied the effect of different nitrogen sources on lipid and other major metabolic pathways in Phaeodactylum tricornutum. We not only optimized the nutritional condition, but also revealed the competitive pathway affecting the lipid synthesis in Phaeodactylum tricornutum. The results showed that urea had the most significant effect on the growth and lipid accumulation of Phaeodactylum tricornutum. The highest lipid content could be obtained in the Modified Basal Medium (MBM) with a ratio of glycine $0.7 \mathrm{~g} / \mathrm{L}$, yeast extract $5 \mathrm{~g} / \mathrm{L}$, urea $0.6 \mathrm{~g} / \mathrm{L}$, glucose $20 \mathrm{~g} / \mathrm{L}$ and the total lipid yield of the optimized group was 202,118.9, 129.4 and $53.3 \%$ higher than the basic medium group from day 2-8. Through the analysis of metabolites, it was found that protein synthesis during the growth of Phaeodactylum tricornutum was the main competitive pathway affecting its biomass and lipid accumulation. This laid a theoretical and practical foundation for the regulation of lipid accumulation in Phaeodactylum tricornutum in the future.
\end{abstract}

Keywords: Phaeodactylum Tricornutum, Nitrogen Source, Lipid Accumulation, Nutritional Ratio, Competitive Pathway

\section{Introduction}

Microalgae has the characteristics of fast growth, easy cultivation, rich sources, high photosynthetic efficiency and high biological yield and is known as one of the most promising new biodiesel raw materials (Song et al., 2008; Chisti, 2007). Among marine diatoms, Phaeodactylum tricornutum is widely studied and its lipid content can reach $10.0 \sim 31.5 \%$ of dry weight. It is an economic algae resource with great $R \& D$ potential and commercial value (Benavides et al., 2013; Gao, 2001).

Marine microalgae are one of the few organisms in nature that can synthesize Polyunsaturated Fatty Acids (PUFAs). Microalgae lipid not only contains higher PUFAs, but also has a simple lipid composition and is easy to separate (Xiamin and Yizhou, 2003). Previous studies have found that the accumulation and composition of fatty acids in microalgae are not only controlled by genes, but also affected by environmental factors (Fang et al., 2004; Reitan et al., 1994). Some studies have also found that microalgae lipid increased when it is in a harsh environment (Zhu et al., 2012). The most significant influencing factors are the type of nitrogen source and its concentration.

Commonly used nitrogen sources in microalgae cultivation include ammonium nitrogen, nitrate nitrogen and organic nitrogen. Different nitrogen sources have different effects on microalgae growth and oil accumulation (Zhang et al., 2016). The optimal nitrogen source for different microalgae lipid accumulation is also different and the content of microalgae lipid components such as saturated and unsaturated fatty acids is also different (Fu et al., 2011). So far, quite a few researchers have studied the microalgae's lipid synthesis pathway, but less research studied the correlation of lipid and other major metabolites during the cultivation process.

In addition, as the world's petroleum resources are increasingly depleted, the development of new energy sources is imminent. As a new renewable green energy source, biodiesel will play an important role in economic development and environmental protection. Meanwhile, study of combustion ashes of different non-wood 
biomass towards concrete production is also a rising research (Matalkah et al., 2017). Microalgae biomass and biodiesel, as environmentally friendly and efficient clean energy in the 21 st century, has been vigorously studied by many countries and laboratories (Cordier et al., 2020). Phaeodactylum tricornutum not only has high lipid content, but could also accumulate a large amount of biomass. Thus, it is of great significance to study the effects of different nitrogen sources on the lipid metaboism in Phaeodactylum tricornutum.

In this study, Phaeodactylum tricornutum was used to study the effect of nitrogen sources on the growth and lipid accumulation, the best nitrogen source and the best nutritional ratio for the growth and lipid accumulation and the competitive metabolites of lipid accumulation were also explored, which provide a reference for the further development of microalgal resources and future large-scale microalgal biodiesel production and research.

\section{Materials and Methods}

\section{Strain and Culture Condition}

The Phaeodactylum tricornutum used in this experiment was derived from algae strains cultivated in the laboratory of Shandong University of Technology. Modified Basal Medium (MBM) with an initial pH 7 was used in all cultures. The MBM medium used in the experiment was formulated with the following ingredients: Glucose $40 \mathrm{~g} \mathrm{~L}^{-1}$, glycine $1 \mathrm{~g} \mathrm{~L}^{-1}$, yeast extract $4 \mathrm{~g} \mathrm{~L}^{-1}, \mathrm{KH}_{2} \mathrm{PO}_{4} 0.7 \mathrm{~g} \mathrm{~L}^{-1}, \mathrm{~K}_{2} \mathrm{HPO}_{4} 0.3 \mathrm{~g} \mathrm{~L}^{-1}$, $\mathrm{MgSO}_{4} \cdot 7 \mathrm{H}_{2} \mathrm{O} 0.3 \mathrm{~g} \mathrm{~L}^{-1}, \mathrm{FeSO}_{4} \cdot 7 \mathrm{H}_{2} \mathrm{O} 0.003 \mathrm{~g} \mathrm{~L}^{-1}$, A5 stock solution $1 \mathrm{ml} \mathrm{L}^{-1}$. The formula of $\mathrm{A} 5$ solution is $\mathrm{H}_{3} \mathrm{BO}_{5} 2.86 \mathrm{mg} \mathrm{L}{ }^{-1}, \mathrm{MnCl}_{2} \cdot 4 \mathrm{H}_{2} \mathrm{O} 1.81 \mathrm{mg} \mathrm{L}-1, \mathrm{ZnCl}_{2}$ $0.105 \mathrm{mg} \quad \mathrm{L}^{-1}, \quad \mathrm{NaMoO}_{4} \cdot 2 \mathrm{H}_{2} \mathrm{O} \quad 0.039 \quad \mathrm{mg} \quad \mathrm{L}^{-1}$, $\mathrm{CuSO}_{4} \cdot 5 \mathrm{H}_{2} \mathrm{O} 0.079 \mathrm{mg} \mathrm{L}{ }^{-1}, \mathrm{CoCl}_{2} 0.003 \mathrm{mg} \mathrm{L}^{-1}$. All cultures were performed at $(20 \pm 1)^{\circ} \mathrm{C}$ under continuous orbital agitation $(150 \mathrm{rpm})$ in a Multitron II incubator (Infors-HT, Bottmingen, Switzerland). Light was provided at $60 \mu \mathrm{mol} \mathrm{m} \mathrm{m}^{-2} \mathrm{~s}^{-1}$ and the light-dark cycle is $12 / 12 \mathrm{~h}$.

\section{Determination of the Best Nitrogen Source}

Three types of nitrogen sources (ammonium chloride, sodium nitrate and urea) were added separately in the basic MBM medium (control group) to reach a nitrogen concentration of $12 \mathrm{mmol} / \mathrm{L}$. All experiments were carried out in triplicates. After a $10 \%$ of inoculation, the cells were cultured in a shaker for 9 days under
$(20 \pm 1)^{\circ} \mathrm{C}$, with continuous orbital agitation $(150 \mathrm{rpm})$ in a Multitron II incubator (Infors-HT, Bottmingen, Switzerland). Light was provided at $60 \mu \mathrm{mol} \mathrm{m} \mathrm{m}^{-2} \mathrm{~s}^{-1}$ and the light-dark cycle is $12 \mathrm{~h} / 12 \mathrm{~h}$.

\section{Optimization of Nutritional Proportion}

The experiment designed a four-factor five-parallel $\mathrm{L}_{25}\left(5^{6}\right)$ orthogonal experiment, the influencing factors included glycine, yeast extract, glucose and nitrogen sources. Each factor was set up with 5 gradients for a total of 25 groups of experiments. A $500 \mathrm{~mL}$ flask with $150 \mathrm{~mL}$ designed medium as in Table 1 was prepared and in each flask, the inoculation amount was $10 \%$, all cultures were put in a shaker for 5 days under conditions of light, $(20 \pm 1)^{\circ} \mathrm{C}, 150 \mathrm{rpm}$. On the fifth day, samples were taken to measure $\mathrm{OD}_{625}, \mathrm{pH}$, biomass concentration and total lipid content.

\section{Cell Concentration Estimation}

Cell concentration of algal culture samples was determined in triplicates by the ultraviolet spectrophotometer, the absorbance of algae culture was measured at a wavelength of $625 \mathrm{~nm}$.

\section{Protein and Carbohydrate Analysis}

Protein content was analyzed by coomassie brilliant blue method (Atherton et al., 1996). 10mL of the culture sample was centrifuged at $8000 \mathrm{rpm}, 4^{\circ} \mathrm{C}$ for $10 \mathrm{~min}$, then the supernatant was removed and cell pellets were washed twice with water. Resuspend the cell pellets in 200 ul water and pulverize the cells with ultrasound. After centrifuging at $8000 \mathrm{rpm}, 4^{\circ} \mathrm{C}$ for $10 \mathrm{~min}, 10-50 \mu \mathrm{L}$ of the supernatant were taken out into a cuvette, in which $1.5 \mathrm{~mL}$ of Coomassie Brilliant Blue was added. Then cover the cuvette with a plastic paraffin seal, mix it by inversions and let it stand for $10 \mathrm{~min}$. Then the absorbance of the mixture was measured at a wavelength of $595 \mathrm{~nm}$ using a UV spectrophotometer. The concentration of the protein in the sample was calculated according to the standard curve.

For the carbohydrate analysis, take a volume of $0.1 \mathrm{~mL}$ sample to $1 \mathrm{~mL}$, add $1 \mathrm{~mL}$ of phenol and $5 \mathrm{~mL}$ of $96 \%$ concentrated sulfuric acid. Let it stand for $10 \mathrm{~min}$ after shaking vigorously and put it in a water bath at $25-30^{\circ} \mathrm{C}$ for $20 \mathrm{~min}$. Then the absorbance of the mixture was measured under a wavelength of $490 \mathrm{~nm}$ using ultraviolet spectrophotometer. The concentration of carbohydrate in the sample was calculated from the standard curve.

Table 1: Nutritional proportion

\begin{tabular}{lllll}
\hline No. & Glycine $(\mathrm{g} / \mathrm{L})$ & Yeast extract $(\mathrm{g} / \mathrm{L})$ & Nitrogen source $(\mathrm{mmol} / \mathrm{L})$ & glucose $(\mathrm{g} / \mathrm{L})$ \\
\hline 1 & 0.4 & 2 & 4 & 20 \\
2 & 0.7 & 3 & 8 & 30 \\
3 & 1.0 & 4 & 12 & 40 \\
4 & 1.3 & 5 & 16 & 50 \\
5 & 1.6 & 6 & 20 & 60 \\
\hline
\end{tabular}




\section{Biomass Estimation and Total Lipid Analysis}

The biomass of the samples was measured using a weighing method. $50 \mathrm{~mL}$ culture was centrifuged at $8000 \mathrm{rpm}, 4^{\circ} \mathrm{C}$ for $10 \mathrm{~min}$ and the collected biomass was washed with distilled water in a small centrifuge tube and centrifuged again to remove medium constituents, then vacuumed to remove extra water. The fresh cell pellets were put in an empty tube (weigh in advance, $\mathrm{W}_{0}$ ) and further lyophilized (VirTis, Advantage Plus EL-85) until the weight of the tube remains unchanged $\left(\mathrm{W}_{1}\right)$, so the cell dry weight could be determined by $\mathrm{W}_{1}-\mathrm{W}_{0}$.

The lipid extraction and determine procedure was adapted from (Folch et al., 1957) method. Briefly, $10 \mathrm{mg}$ of dried cells (lyophilized, see above) were extracted with $6 \mathrm{~mL}$ of chloroform/methanol mixture $(2: 1)$ under ultrasound in ice water for $30 \mathrm{~min}$. Then the mixture was filtered into a new tube and $3 \mathrm{~mL}$ of $0.9 \% \mathrm{NaCl}$ solution was added. Centrifuge the mixture at $10,000 \mathrm{~g}, 0^{\circ} \mathrm{C}$ for 5 min and the lower layer was transferred into the lipid tube (weigh in advance, $\mathrm{W}_{0}$ ). Blow dry the liquid with $\mathrm{N}_{2}$ until the weight of the lipid tube remains unchanged $\left(\mathrm{W}_{1}\right)$ and determine the lipid weight by $\mathrm{W}_{1}-\mathrm{W}_{0}$.

\section{Data Processing}

The experimental data of the first and third stages of this experiment were plotted using the statistical software origin 8 and the second stage was performed by the four-factor five-parallel $\mathrm{L}_{25}\left(5^{6}\right)$ orthogonal test. The results were analyzed and processed using spss 21.0 statistical software.

A flowchart was draw to show the research methodology as follows.

\section{Results and Discussion}

\section{Effects of Different Nitrogen Sources on the Growth of Phaeodactylum tricornutum}

In order to test the effects of different types of nitrogen sources on the growth and lipid accumulation of Phaeodactylum tricornutum, we selected nitrate nitrogen (sodium nitrate), ammonium nitrogen (ammonium chloride) and organic nitrogen (urea) to compare their effects on cell growth and lipid accumulation. Figure 1 clearly shows the cell growth and $\mathrm{pH}$ changes of Phaeodactylum tricornutum culture under different nitrogen sources.

Comparing the OD values of the culture, it can be found that the OD values of the control group, the urea group and the ammonium chloride group are not significantly different, indicating that urea and ammonium chloride have little effect on the change of cell concentration. Interestingly, the $\mathrm{pH}$ values of the four groups of experiments are different. The $\mathrm{pH}$ of the urea and sodium nitrate groups are not much different and higher than the $\mathrm{pH}$ level in the control group.
The reduction process of urea in unicellular algae has been studied. The reduction process is the decomposition of urea into two molecules of $\mathrm{NH}_{3}$, which could increase the $\mathrm{pH}$ level in the culture and one molecule of $\mathrm{CO}_{2}$ under the action of urease. It has been confirmed that urease exist in Phaeodactylum tricornutum cells and when the microalgae use nitrate nitrogen, it will first convert the oxidized nitrate nitrogen to ammonium nitrogen and then use it. This process increases the energy consumption of the microalgae using nitrogen source, which makes it more difficult for the microalgae to use nitrate nitrogen. But the change in $\mathrm{pH}$ is not obvious (Yongmanitchai and Ward, 1991; Meiser et al., 2004). Therefore, it explained the higher $\mathrm{pH}$ level in urea group and nitrate groups than that in the control.

Although the $\mathrm{pH}$ gap between control and the ammonium chloride group is not large, the data in ammonium chloride group is always lower than the control group, which indicates that the $\mathrm{pH}$ value of the culture solution is reduced when the ammonium chloride is used by microalgae. Previous studies have shown that microalgal cells can directly use ammonia to combine with carbohydrates in the cell to generate amino acids. Among the three nitrogen sources, ammonium nitrogen is the nitrogen source closest to ammonia and the process of changing from ammonium ion to ammonia is almost no energy consumption is required and $\mathrm{NH}_{4}{ }^{+}$can be combined with $\mathrm{OH}^{-}$hydrolyzed to form hydrated ammonia, which enters the cell and participates in material metabolism. Although there is almost no hindrance to this process, as the cell absorbs more and more ammonia hydrate, the hydrolysis of the remaining $\mathrm{H}^{+}$will cause the $\mathrm{pH}$ of the surrounding environment of the cell to drop (Li, 2017).

Interestingly, the cell concentrations of the urea, ammonium chloride and control groups did not show significant differences even when grown at different pHs, possibly due to when microalgal cells at lower $\mathrm{pHs}$, it may due to that the sensitivity of cell growth to $\mathrm{pH}$ is no longer significant and other factors have become more significant when cells grow under low $\mathrm{pH}$ level. At the same time, we found that Phaeodactylum tricornutum could still grow well even at a lower $\mathrm{pH}$, indicating that the $\mathrm{pH}$ range of Phaeodactylum tricornutum was wide, which provided a basis for the growth of Phaeodactylum tricornutum under lower $\mathrm{pH}$ environment.

However, from the result, we could see that sodium nitrate is not conducive to the cell growth. Previous studies have shown that nitrate nitrogen is highly oxidized and algae must convert the highly oxidized nitrate nitrogen to a highly reduced state before it can be absorbed and used (Bougis, 1976; Brown and Johnson, 1977), which makes it difficult for microalgae to use. The result of this experiment is similar to that obtained 
by (Zhang et al., 2016) According to the comparison of the nutritional components of the control group and the sodium nitrate group, it was found that the only nitrogen source in the control group was glycine and the Free Amino Acids (DFAA) contained in yeast extract.

Fan et al. (2003) stated that DFAA can be directly used by algae. For example, (Linares, 2006) study has shown that diatoms absorb a certain proportion of DFAA during reproduction, they also absorb large amounts of DFAA when other nutrients are deficient. Lu and Ji (1997) showed that Chlorella is not only the main producer of DFAA in seawater, but also the consumer of DFAA. However, the addition of sodium nitrate and nitrate have counteract effect on the amino acid nutrition to algae cells, which indicates that sodium nitrate may have a toxic effect on cell growth. Zhao et al. (2016) found that high concentrations of sodium inhibit cell growth through carbon cycling of the cells and this conclusion is also consistent with our result.

In order to further explore the mechanism of nitrogen source on the biomass and lipid accumulation of Phaeodactylum tricornutum, we also tested the biomass and lipid accumulation of Phaeodactylum tricornutum (Fig. 2). Results showed a large difference of lipid accumulation at low $\mathrm{pH}$ level.

Results show that biomass concentration was the highest with urea as the nitrogen source and was the lowest with sodium nitrate as nitrogen source. Combined with $\mathrm{pH}$ result, the $\mathrm{pH}$ levels were similar in urea and sodium nitrate group, which further indicate that nitrate nitrogen inhibited the growth of Phaeodactylum tricornutum. However, biomass concentration showed no big difference in the ammonium chloride and control group, which with similar $\mathrm{pH}$ levels.
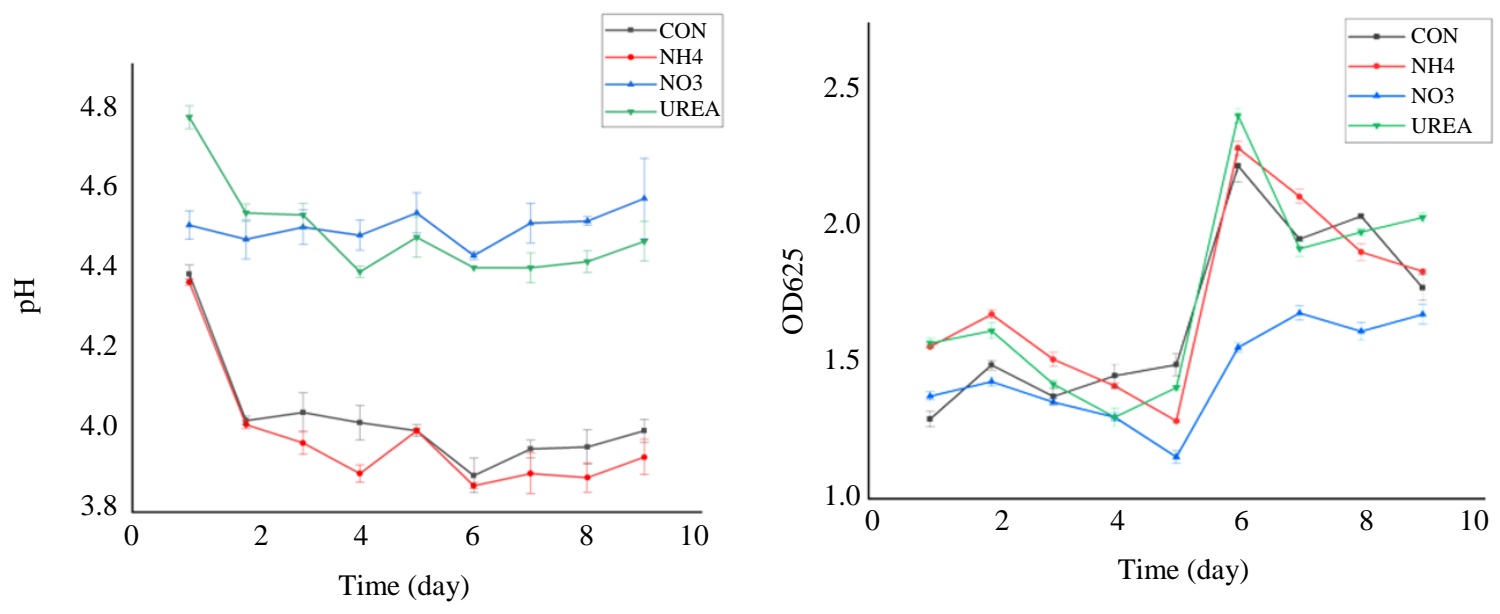

Fig. 1: Culture $\mathrm{pH}$ and growth condition of Phaeodactylum tricornutum $\left(\mathrm{CON}\right.$ : control group; $\mathrm{NH}_{4}$ : ammonium chloride group; $\mathrm{NO}_{3}$ : ammonium nitrate group; UREA: urea group)
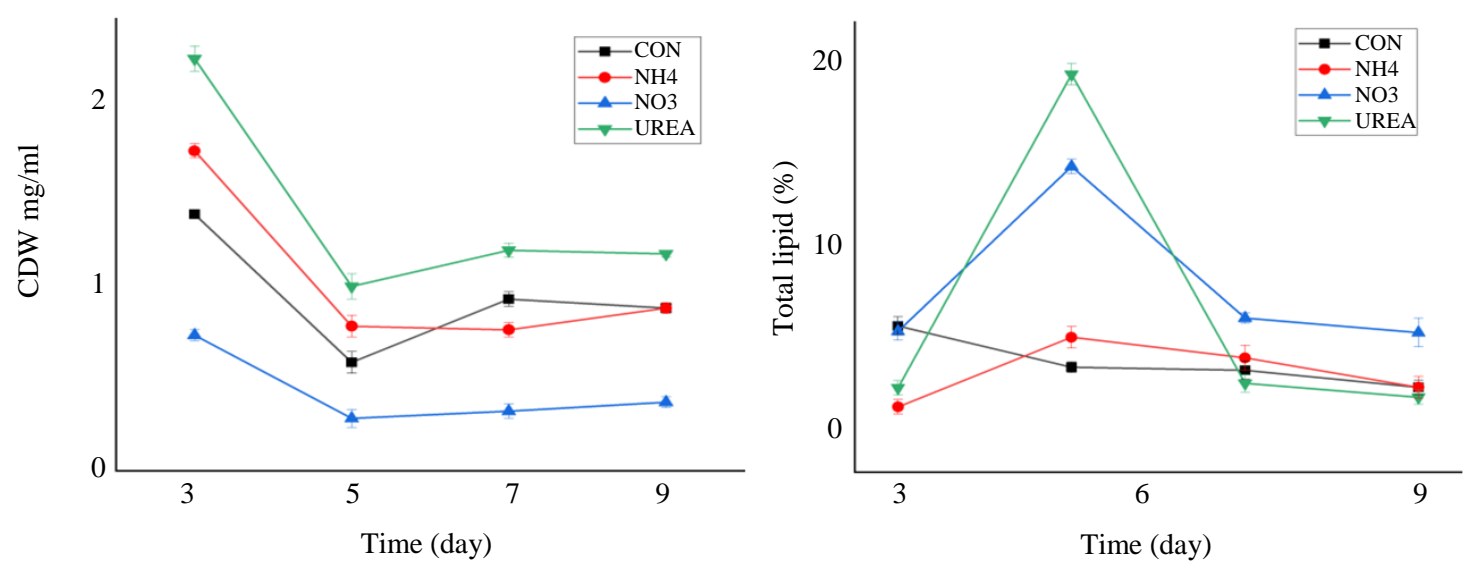

Fig. 2: Biomass and lipid accumulation of Phaeodactylum tricornutum 
At the same time, we found that biomass concentration in the four groups showed larger differences compared with those in $\mathrm{OD}_{625}$ of the culture, which indicate that $\mathrm{OD}_{625}$ and biomass concentration are not linearly related. Griffiths et al. (2011) has shown that microalgae density $\mathrm{OD}_{625}$ and biomass concentration are not strictly positively related. This has a greater relationship with the cell morphology and inclusion of the cells in the logarithmic growth phase. We found that biomass concentration in the four groups dropped to the lowest value on the 5th day and were more stable after that. The trend of lipid accumulation and biomass change is opposite. The biomass concentration decreases during lipid accumulation. Interestingly, in the sodium nitrate group, where the biomass concentration and the $\mathrm{OD}_{625}$ were both low, the lipid accumulation had been tending to a high level, which was lower than the urea group only on the fifth day. So, while inhibiting the growth of Phaeodactylum tricornutum, sodium nitrate promoted the synthesis of lipid.

This is similar to the growth and accumulation of lipids of most microalgae under harsh conditions. Many studies have clarified that environmental factors play a key role in the growth of algal strains and the accumulation of lipids. Limitations of environmental factors have been proven to improve lipid in cells (Gardner et al., 2012; Santos et al., 2012). At the same time, we can also see that when the biomass concentration of the other three groups of microalgae was reduced to the minimum (day 5), the accumulation of lipid reached the highest value, which further proved this point. Therefore, the accumulation of microalgae lipids has a potential role in the cellular stress resistance process.

Although ammonium chloride and urea groups revealed no significant difference in the OD values compared with the control group, the biomass concentration in these two groups were much higher than that in the control group. Meanwhile, the lipid content was significantly higher in the urea group compared with the control and ammonium chloride group, in which two, the lipid contents are in the same level. This indicates that urea is the best nitrogen source for biomass and lipid accumulation for Phaeodactylum tricornutum.

In addition, we examined the synthesis of two other macromolecules, proteins and carbohydrates, that make up microalgal cells. Results (Fig. 3) show that protein and carbohydrate were both highest in the soudium nitrate group.

The protein content reached $412 \mathrm{mg} / \mathrm{g}$ CDW and the carbohydrate content reached $314.6 \mathrm{mg} / \mathrm{g}$ CDW on the fifth day. These two values are respectively much higher than the $263 \mathrm{mg} / \mathrm{g} \mathrm{CDW}$ and $162.6 \mathrm{mg} / \mathrm{g} \mathrm{CDW}$ in the control group. The protein content and carbohydrate content of the urea group from day 3 to day 9 have been at the lowest level in the four groups, but the biomass concentration and total lipid content of the same period are the highest of the four groups. Therefore, urea is the best nitrogen source for the biomass and lipid accumulation of Phaeodactylum tricornutum. In addition, the protein content in the ammonium chloride group and the urea group almost coincide and are lower than those of the control group.

Comparing the accumulation of Phaeodactylum tricornutum in biomass, protein, carbohydrates and lipids during the cultivation process, we could found that the peaks of these component occurred at the same time on the fifth day. The urea group showed the highest level of lipid accumulation on the fifth day but the lowest level of carbohydrate and protein accumulation. At the same time, it can be found that the sodium nitrate group whose biomass concentration has always been at a lower level showed higher protein, lipid and carbohydrate accumulation levels. Comparing the growth of Phaeodactylum tricornutum in the other two groups, it was found that although the control group and the ammonium chloride group had lower lipid accumulation levels, they also had higher protein and carbohydrate accumulation levels. The comprehensive result showed that the accumulation of lipid have a certain degree of competition with protein and carbohydrate. At the same stage, Phaeodactylum tricornutum, which synthesizes more proteins and carbohydrates, will reduce its biomass concentration and total lipid content and vice versa.

\section{Determination of the Optimal Nutrition Proportion}

There are various factors that affect the growth and lipid accumulation in microgalge. Lipid synthesis and metabolism is a complex process catalyzed by a variety of enzymes. Each enzyme and its metabolite may affect the efficiency and stability of the metabolic chain. Pan et al. (2001) reported that nutritional components of the surrounding environment will affect the efficiency of the metabolism and there may be interactions between certain influencing factors. Therefore, it is impossible to determine the optimal conditions for the growth and lipid accumulation of microalgae by investigating the effects of a single nitrogen source on the lipid production. Comprehensive research must be conducted in combination with various nutritional factors to determine the exact factors affecting lipid synthesis. Therefore, the three major components in the MBM medium and the optimal nitrogen source that have been determined are selected as factors to investigate the best proportion of nutritional components for Phaeodactylum tricornutum growth and lipid accumulation. 

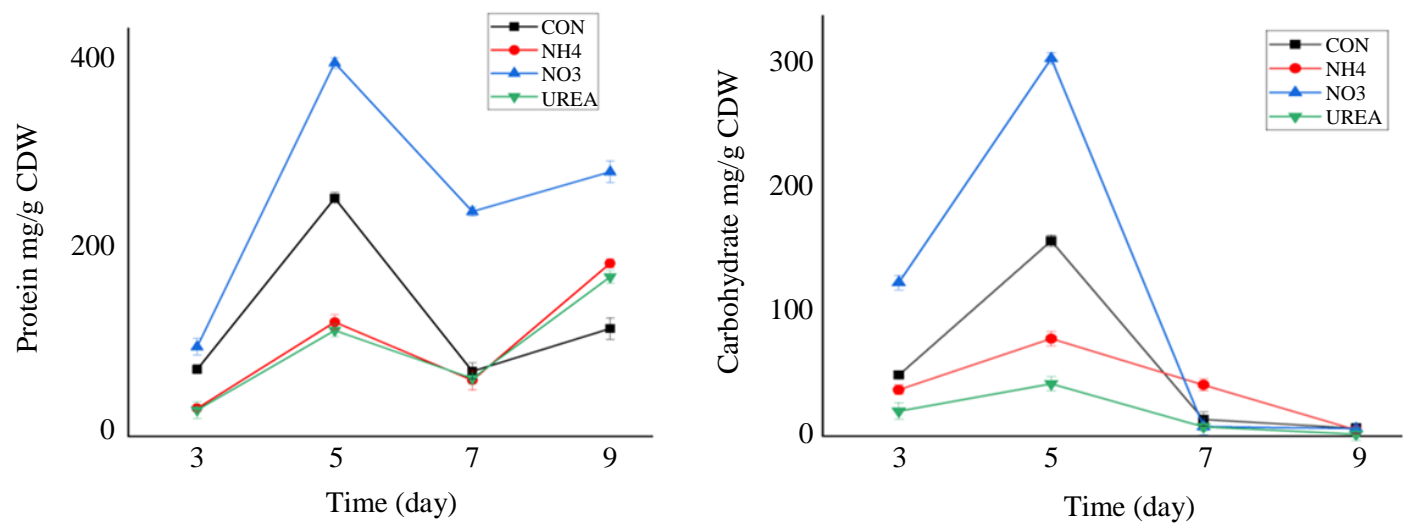

Fig. 3: Carbohydrate and protein accumulation during Phaeodactylum tricornutum cultivation

Table 2: Orthogonal test result

\begin{tabular}{|c|c|c|c|c|c|c|c|c|c|}
\hline \multirow[b]{2}{*}{$\begin{array}{l}\text { Process } \\
\text { number }\end{array}$} & \multicolumn{5}{|l|}{ Factor } & \multicolumn{4}{|c|}{ Experimental results } \\
\hline & Glycine & $\begin{array}{l}\text { Yeast } \\
\text { Extract }\end{array}$ & Urea & Glucose & $\begin{array}{l}\text { Empty } \\
\text { column }\end{array}$ & $\begin{array}{l}\text { Biomass } \\
(\mathrm{mg} / \mathrm{ml})\end{array}$ & $\begin{array}{l}\text { Carbohydrate } \\
(\mathrm{mg} / \mathrm{g} \text { CDW) }\end{array}$ & $\begin{array}{l}\text { Protein } \\
(\mathrm{mg} / \mathrm{g} \text { CDW) }\end{array}$ & $\begin{array}{l}\text { Lipid } \\
(\%)\end{array}$ \\
\hline 1 & 1 & 1 & 1 & 1 & 1 & 2.06 & 13.723 & 61.165 & 5.83 \\
\hline 2 & 1 & 2 & 2 & 2 & 2 & 2.26 & 14.677 & 97.345 & 11.5 \\
\hline 3 & 1 & 3 & 3 & 3 & 3 & 2.25 & 19.937 & 56.522 & 6.96 \\
\hline 4 & 1 & 4 & 4 & 4 & 4 & 2.04 & 15.300 & 186.111 & 9.26 \\
\hline 5 & 1 & 5 & 5 & 5 & 5 & 2.38 & 12.466 & 196.639 & 8.40 \\
\hline 6 & 2 & 1 & 2 & 3 & 4 & 3.12 & 17.145 & 58.974 & 1.92 \\
\hline 7 & 2 & 2 & 3 & 4 & 5 & 2.62 & 9.778 & 112.214 & 6.11 \\
\hline 8 & 2 & 3 & 4 & 5 & 1 & 2.56 & 15.948 & 112.500 & 7.81 \\
\hline 9 & 2 & 4 & 5 & 1 & 2 & 4.08 & 12.460 & 83.333 & 9.31 \\
\hline 10 & 2 & 5 & 1 & 2 & 3 & 2.24 & 20.108 & 18.750 & 8.93 \\
\hline 11 & 3 & 1 & 3 & 5 & 2 & 2.02 & 15.346 & 41.584 & 7.92 \\
\hline 12 & 3 & 2 & 4 & 1 & 3 & 2.56 & 13.476 & 112.500 & 6.25 \\
\hline 13 & 3 & 3 & 5 & 2 & 4 & 2.76 & 15.062 & 37.681 & 2.90 \\
\hline 14 & 3 & 4 & 1 & 3 & 5 & 1.80 & 24.492 & 58.889 & 8.89 \\
\hline 15 & 3 & 5 & 2 & 4 & 1 & 2.62 & 5.040 & 48.092 & 4.58 \\
\hline 16 & 4 & 1 & 4 & 2 & 5 & 2.32 & 12.454 & 28.448 & 5.17 \\
\hline 17 & 4 & 2 & 5 & 3 & 1 & 2.88 & 1.967 & 45.139 & 4.17 \\
\hline 18 & 4 & 3 & 1 & 4 & 2 & 2.88 & 10.315 & 32.639 & 5.56 \\
\hline 19 & 4 & 4 & 2 & 5 & 3 & 3.46 & 6.258 & 9.249 & 3.47 \\
\hline 20 & 4 & 5 & 3 & 1 & 4 & 4.26 & 4.713 & 36.697 & 3.67 \\
\hline 21 & 5 & 1 & 5 & 4 & 3 & 2.12 & 19.547 & 86.792 & 3.77 \\
\hline 22 & 5 & 2 & 1 & 5 & 4 & 2.28 & 8.843 & 60.526 & 5.26 \\
\hline 23 & 5 & 3 & 2 & 1 & 5 & 2.94 & 12.836 & 25.850 & 4.08 \\
\hline 24 & 5 & 4 & 3 & 2 & 1 & 3.60 & 2.277 & 16.111 & 3.33 \\
\hline 25 & 5 & 5 & 4 & 3 & 2 & 4.30 & 5.023 & 92.558 & 4.65 \\
\hline
\end{tabular}

According to the results of the first-stage experiment, it can be concluded that the fifth day is the stage in which the biological indicators of Phaeodactylum tricornutum are relatively high, so the test was done on the fifth day. At this stage, the correlation between different factors on biomass, lipid, carbonhydrate and protein of Phaeodactylum tricornutum was analyzed while the optimal nutritional proportion was obtained (Table 2).

It can be seen from Table 2 that the highest lipid content was in the second group $(11.5 \% \mathrm{CDW})$. However, combined with the biomass concentration in the same group, which is only $1.13 \mathrm{mg} / \mathrm{mL}$, the total lipid per liter of algae culture will be only $13 \mathrm{mg}$. The 9 th group in the experiment has a lipid content of $9.31 \% \mathrm{CDW}$ and the biomass concentration of the 9th group is as high as 2.04 $\mathrm{mg} / \mathrm{mL}$, which is almost twice that of the 3rd group. The total lipid yield in the medium was $19 \mathrm{mg} / \mathrm{L}$, which was $46 \%$ higher than that in the second group. Therefore, the culture conditions of the ninth group were selected as the optimal nutritional proportion for Phaeodactylum tricornutum. Compared with the control group, the biomass was $33.6 \%$ higher and the total lipid yield was $94 \%$ higher than that in the basic MBM medium. The nutritional proportion was shown in Table 3. 
Table 3: Optimum propotion of components for Phaeodactylum tricornutum

\begin{tabular}{lllll}
\hline Component & Glycine & Yeast extract & Urea & Glucose \\
\hline concentration & $0.7 \mathrm{~g} / \mathrm{L}$ & $5 \mathrm{~g} / \mathrm{L}$ & $0.60 \mathrm{~g} / \mathrm{L}$ & $20 \mathrm{~g} / \mathrm{L}$ \\
\hline
\end{tabular}
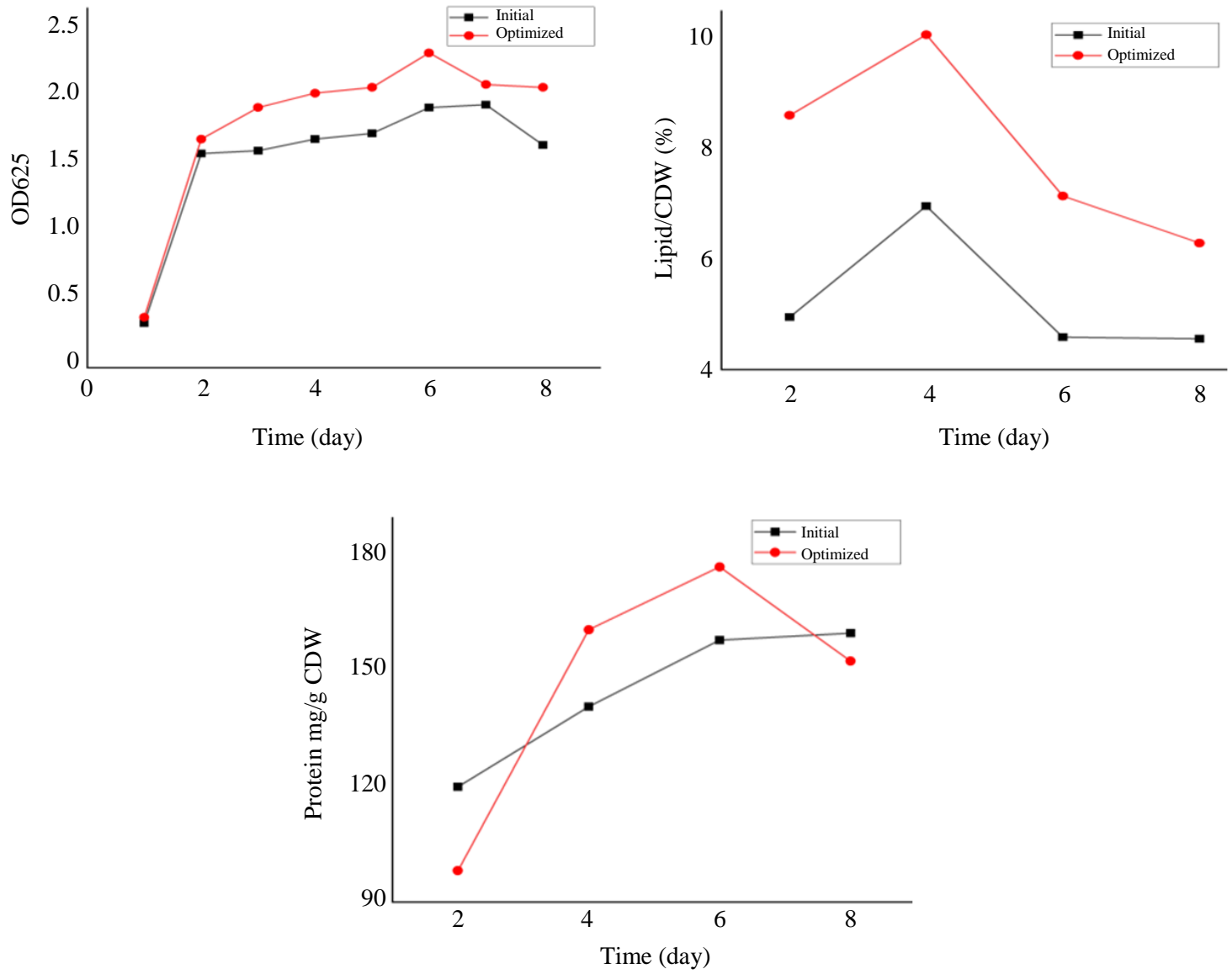

Fig. 4: Comparison of the indicators of the advantage group and the basic group. (Initial: Basic MBM medium; Optimized: Optimized culture medium)

Through orthogonal experiments, we can also calculate the $R$ value, degrees of freedom df and $F$ value according to the experimental results to determine the significance of each factor on the biological indicators (biomass, lipid, carbonhydrate and protein). According to previous research, the larger the $\mathrm{R}$ value, the more significant the influence of factors on biological indicators. From the R-values of the four factors affecting Phaeodactylum tricornutum (Supplementary file), it can be seen that the order of the four nutrients affecting biomass concentration is: Glycine > yeast extract $>$ glucose $>$ urea. In terms of lipid accumulation, $\mathrm{R}$ value of urea group is greater than other factors and the main order is urea > glycine > yeast extract > glucose, indicating that urea has a greater effect on the lipid accumulation. At the same time, we found that glycine also affects proteins and carbohydrates, which also explained that proteins and carbohydrates have strong antagonistic competition with lipid accumulation as conclusions proposed in the first stage.

Quantitative Analysis of Optimal Nutrition on the Lipid Accumulation of Phaeodactylum tricornutum

Based on the results obtained above, the Phaeodactylum tricornutum was cultured under the optimized culture medium. From Fig. 4 it can be seen that the biomass concentration and lipid content of the optimized culture group are much higher than those in the basic MBM medium. The biomass concentration from day 2-8 was 37.2, 28.7, 16.7 and $26.5 \%$ higher than the basic medium group, respectively and the optimized culture group showed a higher growth rate. In the lipid content in the optimized culture group was 120.87, $60.90,93.29$ and $64.90 \%$ higher than the basic medium group from day $2-8$, respectively. Combined with the biomass concentration and the lipid content, the 
advantage of the optimized culture group will be greater. The lipid yield of the optimized group is $139,162,78,64$ and $64 \mathrm{mg}$ per liter of culture medium, respectively. Compared with 46, 74, 34 and $30 \mathrm{mg}$ in the basic medium group, the lipid yield of the optimized group was 202, 118.9, 129.4 and $53.3 \%$ higher than the basic medium group, which is a considerable improvement.

\section{Conclusion}

In this study, urea was determined to be the best nitrogen source for the accumulation of biomass and lipid in Phaeodactylum tricornutum. Then, an orthogonal test of four factors and five levels was performed based on the basic medium and the optimal nutrient proportion for the accumulation of lipid and biomass was determined. Cultivation of Phaeodactylum tricornutum with the optimized proportion as $0.7 \mathrm{~g} / \mathrm{L}$ of glycine, 5 $\mathrm{g} / \mathrm{L}$ of yeast extract, $0.6 \mathrm{~g} / \mathrm{L}$ of urea and $20 \mathrm{~g} / \mathrm{L}$ of glucose yields the highest of lipid and the lipid yield of the optimized group was 202, 118.9, 129.4 and 53.3\% higher than the basic medium group from day 2-8, which is a considerable improvement. Finally, through the analysis of other metabolites, it was concluded that protein synthesis during the growth of Phaeodactylum tricornutum was the main competitive pathway affecting biomass and lipid accumulation, laying a theoretical foundation for the regulation of lipid accumulation. This study has important theoretical guidance and practical application value for future improvement of cultivation in Phaeodactylum tricornutum.

\section{Acknowledgement}

The authors are grateful to the funding support from China Post-doctoral Science Foundation (Grant No. 2019M650167), Shandong Provincial Natural Science Foundation, China (Grant No. ZR2019BC099), China Postdoctoral Science Foundation (Grant No. 2019M662362), Innovation Project Special Fund for Post Doctors of Shandong Province, China (Grant No. 201902048).

\section{Author's Contributions}

Xiaojie Ren and Qi Yan: Participated in the whole experiment process and also contributed to the interpretation of the results and manuscript preparation.

Song Li, Yusuf Nazir and Hafiy Halim: Participated in part of the experiment.

Xinhe Zhao and Yuanda Song: Contributed to the guidance of experiment design and ameliorated the manuscript.

\section{Ethics}

This article is original and contains unpublished material. The corresponding author confirms that all of the other authors have read and approved the manuscript and no ethical issues involved.

\section{References}

Atherton, B. A., Cunningham, E. L., \& Splittgerber, A. G. (1996). A mathematical model for the description of the Coomassie Brilliant Blue protein assay. Analytical biochemistry, 233(2), 160-168.

Benavides, A. M. S., Torzillo, G., Kopecký, J., \& Masojídek, J. (2013). Productivity and biochemical composition of Phaeodactylum tricornutum (Bacillariophyceae) cultures grown outdoors in tubular photobioreactors and open ponds. Biomass and bioenergy, 54, 115-122.

Bougis, P. (1976). Marine plankton ecology. NorthHolland Pub. Co..

Brown, C. M., \& Johnson, B. (1977). Inorganic nitrogen assimilation in aquatic microorganisms. In Advances in aquatic microbiology (pp. 49-114). Academic Press.

Chisti, Y. (2007). Biodiesel from microalgae. Biotechnology advances, 25(3), 294-306.

Cordier, C., Guyomard, K., Stavrakakis, C., Sauvade, P., Coelho, F., \& Moulin, P. (2020). Culture of Microalgae with Ultrafiltered Seawater: A Feasibility Study. SciMedicine Journal, 2(2), 56-62.

Fan, C., Glibert, P. M., \& Burkholder, J. M. (2003). Characterization of the affinity for nitrogen, uptake kinetics and environmental relationships for Prorocentrum minimum in natural blooms and laboratory cultures. Harmful Algae, 2(4), 283-299.

Fang, X., Wei, C., Zhao-Ling, C., \& Fan, O. (2004). Effects of organic carbon sources on cell growth and eicosapentaenoic acid content of Nannochloropsis sp. Journal of Applied Phycology, 16(6), 499-503.

Folch, J., Lees, M., \& Stanley, G. S. (1957). A simple method for the isolation and purification of total lipides from animal tissues. Journal of biological chemistry, 226(1), 497-509.

Fu, R., Huang, C. G., \& Wang, H. Y. (2011). Effects of nutritions on growth and oil accumulation of phaeodactylum tricornutum. Hubei Agricultural Sciences, (11), 43.

Gao, Y. H. (2001). Studies on taxonomy, ecology and bioactive products of marine microalgae. JOURNAL-XIAMEN UNIVERSITY NATURAL SCIENCE, 40(2), 573-584.

Gardner, R. D., Cooksey, K. E., Mus, F., Macur, R., Moll, K., Eustance, E., ... \& Peyton, B. M. (2012). Use of sodium bicarbonate to stimulate triacylglycerol accumulation in the chlorophyte Scenedesmus sp. and the diatom Phaeodactylum tricornutum. Journal of applied phycology, 24(5), 1311-1320. 
Griffiths, M. J., Garcin, C., van Hille, R. P., \& Harrison, S. T. (2011). Interference by pigment in the estimation of microalgal biomass concentration by optical density. Journal of microbiological methods, 85(2), 119-123.

Li, P. F. (2017). Research on ammonium salt polyculture to promote the growth and oil accumulation of Nannochloropsis [D]. South China University of Technology.

Linares, F. (2006). Effect of dissolved free amino acids (DFAA) on the biomass and production of microphytobenthic communities. Journal of Experimental Marine Biology and Ecology, 330(2), 469-481.

Lu, T. S., \& Ji, M. H. (1997). Changes of Dissolved Free Amino Acids in Seawater During the Growth of Ceratocystis spp. Ocean and Lakes, 03, 256-261.

Matalkah, F., Darsanasiri, A. G. N. D., Abideen, S., Balachandra, A., \& Soroushian, P. (2017). AlkaliActivation of Non-Wood Biomass Ash: Effects of Ash Characteristics on Concrete Performance. Civil Engineering Journal, 3(5), 365-371.

Meiser, A., Schmid-Staiger, U., \& Trösch, W. (2004). Optimization of eicosapentaenoic acid production byPhaeodactylum tricornutumin the flat panel airlift (FPA) reactor. Journal of applied phycology, 16(3), 215-225.

Pan, T. S., Hu, X. J., \& Hou, G. J. (2001). Effects of nitrogen on the growth of Chlorella vulgaris. Anhui Agricultural Science, 29 (4), 548-555.

Reitan, K. I., Rainuzzo, J. R., \& Olsen, Y. (1994). Effect of nutrient limitation on fatty acid and lipid content of marine microalgae 1. Journal of Phycology, 30(6), 972-979.

Santos, A. M., Janssen, M., Lamers, P. P., Evers, W. A. C., \& Wijffels, R. H. (2012). Growth of oil accumulating microalga Neochloris oleoabundans under alkaline-saline conditions. Bioresource Technology, 104, 593-599.
Song, D., Fu, J., \& Shi, D. (2008). Exploitation of oilbearing microalgae for biodiesel. Chinese Journal of Biotechnology, 24(3), 341-348.

Xiamin, J., \& Yizhou, Z. (2003). Total lipid and fatty acid composition of 14 species of mircoalgae. Shui Sheng Sheng wu Hsueh bao= Acta Hydrobiologica Sinica, 27(3), 243-247.

Yongmanitchai, W. A. R. D., \& Ward, O. P. (1991). Growth of and omega-3 fatty acid production by Phaeodactylum tricornutum under different culture conditions. Applied and environmental microbiology, 57(2), 419-425.

Zhang, W. Y., Gao, B. Y., Li, A. F., \& Zhang, C. W. (2016). Effects of different culture conditions on growth and accumulation of bioactive compounds by Phaeodactylum tricornutum. Marine Sciences, (5), 8.

Zhao, X., Condruz, S., Chen, J., \& Jolicoeur, M. (2016). A quantitative metabolomics study of high sodium response in Clostridium acetobutylicum ATCC 824 acetone-butanol-ethanol (ABE) fermentation. Scientific reports, 6, 28307.

Zhu, Y., Song, D., \& Yang, G. (2012). Effects of different nitrogen sources on growth and lipid accumulation of a heterotrophic microalgaeChorella vulgaris. Acta Hydrobiologica Sinica, 36(6), 1027-1034

\section{Nomenclature}

MBM: Modified Basal Medium

PUFA: Poly Unsaturated Fatty Acids

OD $_{625}$ : Optimal Density under a light wavelength of $625 \mathrm{~nm}$

DFAA: Dissolved Free Amino Acids

CDW: Cell Dry Weight 